\title{
THE IMPACT OF COVID-19 ON THE ORTHOPEDIC CARE SYSTEM IN A PRIVATE HOSPITAL
}

\section{O IMPACTO DA COVID-19 NO SISTEMA DE ATENDIMENTO ORTOPÉDICO EM UM HOSPITAL PRIVADO}

\author{
Henrique Von Rondow de Queiroz ${ }^{1}$ (i), Nilo EiJ Nakamura Toldo ${ }^{1}$ (i), Bruna Gabriela Passarini de Oliveira ${ }^{1}$ (i), \\ Marcos VINICIUS FELIX SANTANA ${ }^{2}$ [D, EIfFel TSUYOSHI DOBASHI ${ }^{1,3}$ (1)
}

1. IFOR Hospital, Rede D'Or São Luiz, São Bernardo do Campo, SP, Brazil.

2. Brazilian Society of Orthopedics and Traumatology, São Paulo, SP, Brazil.

3. Federal University of São Paulo, Escola Paulista de Medicina, Department of Orthopedics and Traumatology, São Paulo, SP, Brazil.

\section{ABSTRACT}

Objective: To evaluate and compare the patient flow in the emergency department and the number of surgeries performed, as well as to determine the incidence of diseases due to the impact generated by the pandemic in April, May, June, and July 2020. Methods: This is a retrospective cross-sectional study that analyzed medical records using the TASY Phillips software. The 2019 information was compiled and served as a basis accomplish our comparative analyses. The ICD-10 was used to determine the different conditions considering the highest incidence of them. Results: there was a reduction in attendance of $49.3 \%$; the reduction in the number of surgeries was $34.39 \%$; among the main diagnoses in decreasing order were: Pain in the Lumbar Spine (18.76\%), Joint Pain (14.82\%), Neck Pain (7.7\%), Ankle Sprain (4.2\%) and Pain in the Limb (3.54\%). Conclusion: There was a decrease in the number of visits and the overall incidence of surgeries in our service. Level of Evidence II, Retrospective Study.

Keywords: Coronavirus. Epidemiology. Epidemiology, Descriptive. Demography. Traumatology. Emergency Medical Services.

\section{RESUMO}

Objetivo: Avaliar e comparar o fluxo de pacientes no pronto-socorro e o número de cirurgias, bem como determinar a incidência das doenças pelo impacto gerado pela pandemia nos meses de abril, maio, junho e julho de 2020. Métodos: Trata-se de estudo retrospectivo transversal que analisou prontuários médicos por meio do software TASY Phillips. Foram compiladas as informações do ano de 2019, que serviram como base para realizar as análises comparativas. Foi utilizado o CID-10 para determinar as diferentes afecções de maior incidência. Resultados: Houve redução nos atendimentos de 49,3\%; a redução do número de cirurgias foi 34,39\%; os principais diagnósticos em ordem decrescente foram: dor na coluna lombar (18,76\%), dor articular (14,82\%), cervicalgia (7,7\%), entorse de tornozelo (4,2\%) e dor no membro (3,54\%). Conclusão: Houve decréscimo do número de atendimentos e da incidência global de cirurgias em nosso serviço. Nível de Evidência II, Estudo Retrospectivo.

Descritores: Coronavírus. Epidemiologia. Epidemiologia Descritiva. Demografia. Traumatologia. Serviços Médicos de Emergência.

Citation: Queiroz HVR, Toldo NEN, Oliveira GP, Santana MVF, Dobashi ET. The impact of Covid-19 on the orthopedic care system in a private hospital. Acta Ortop Bras. [online]. 2021;29(6):289-292. Available from URL: http://www.scielo.br/aob.

\section{INTRODUCTION}

Coronavirus has a high spread, and viral transmission from person to person through droplets of saliva, coughing, phlegm, sneezing, through the contact of infected objects and surfaces with the mouth, nose and eyes causes Covid-19.1-11

Due to its severity and the high speed of virus propagation, the World Health Organization declared the disease caused by SARS-Cov-2 as a pandemic, since its worldwide spread could cause an intense outbreak, spreading in a sustained way, from person to person, across all continents of the planet. ${ }^{7,8,12,13}$

Faced with this unprecedented situation, government authorities began to adopt strategies to reduce the rate of spread of the disease, including social distancing, the use of masks and quarantine, which is the most restrictive measure, where there is an express prohibition for holding events that bring together a large number of individuals. Soon, activities in schools, universities, concerts, shopping malls, cinemas, sports academies, sporting events were deliberately canceled. ${ }^{9,14,15,19}$ In the state of São Paulo, the government decreed quarantine on March 24, 2020, keeping only essential food, health, supply, banking, cleaning, security and transport services open. These measures caused a considerable and sensitive decrease in the flow of people on the streets and, especially, in emergency services throughout the country.

Among the measures adopted by the government, there was the creation of protocols to provide services safely for patients and health professionals.

All authors declare no potential conflict of interest related to this article.

The study was conducted at Hospital IFOR Rede D'Or.

Correspondence: Henrique Von Rondow de Queiroz. Avenida Jamaris, 543, ap. 176, Jardim Planalto, São Paulo, SP, Brazil, 04078-000. vonrondow@hotmail.com.br 
The collective fear of the population determined a considerable reduction in consultations, where many of them were no longer considered priorities, which prevented patients from going to the emergency room for fear of contamination within the hospital. ${ }^{7,20}$ The assistance in emergency medical services is crucial for any health system, where the premise is to offer the population immediate emergency care and treatment, safely and efficiently.

The reduction in the number of consultations in other pandemic outbreaks resulted in a noticeable reduction in visits and hospitalizations, for example, in primary coronary interventions. ${ }^{15,16,17}$

The scarcity and novelty on this topic encouraged researchers to carry out this study. Therefore, the primary objective of this article is to evaluate the effects of Covid-19 on the frequency of patients seen in our emergency room service, and compare it with the flow of visits in the same period in the previous year (2019).

Among the secondary objectives, we shall analyze: the influence of the pandemic on the number of surgeries in orthopedic traumatology, and the incidence of diseases according to the International Code of Diseases (ICD 10) considering the same period defined for the study.

\section{MATERIAL AND METHODS}

This research project was submitted for analysis by the Research Ethics Committee of Plataforma Brasil under registration CAEE 39593320.4.0000.5625, and approved for execution by opinion 4,367,294.

This is a retrospective longitudinal study where the analysis of digital records of patients seen in the emergency room of our Service was performed. Information obtained from the Medical Archive and Statistics Service of patients who underwent surgical treatment in the area of Orthopedic Trauma was also compiled.

The diagnoses of conditions of the patients treated were cataloged, and the search considered the diseases coded by ICD 10.

The period of our evaluation study comprised the months of April, May, June and July 2020, when the pandemic occurred, and the same months of 2019 that were used so that the appropriate comparisons could be made.

For the selection of patients and medical records, the following inclusion criteria were used:

1. Patients of both sexes;

2. All ages;

3. With care in the emergency room for complaints related to disorders of the locomotor system;

4. Patients undergoing surgical procedures from the emergency room. We consider the following criteria for non-inclusion of patients:

1. Patients with incomplete medical records;

2. Patients with emergency room care without locomotor disorders; Quantitative analyses, comparisons and the necessary data collected were compiled and tabulated for further analysis, considering: age, sex, diagnosis and surgery.

We use the TASY PHILIPS - HEALTH MANAGEMENT SYSTEM medical record management program to extract information that is used in all registration processes.

\section{RESULTS}

The total number of patients seen in 2019 was 21,883 . Of these, 10,885 (49.61\%) patients were male and 11,028 (50.29\%) were female. The average age was 41 years (minimum 1 and maximum 102 years). The distribution of care in the emergency room, according to the months of April, May, June and July was respectively 5,701 (26.05\%), 5,836 (26.73\%), 5,228 (23.89\%) and 5,118 (23.44\%). Information on the distribution of our material considering the control period is shown in Graph 1.
The total number of patients seen in 2020 during the pandemic period was 11,096 . Of these, $5,177(46.66 \%)$ patients were male and 5,919 (53.34\%) were female. The average age in this period was 43 years (minimum of 1 and maximum of 99 years). The distribution of care in the emergency room, according to the months of April, May, June and July was respectively 2,466 (22.22\%), 2,393 (21.56\%), 2,802 (25.25\%) and 3,435 (30.95\%). The information on the distribution of our sample, considering the period of the pandemic, is shown in Graph 1.

Graph 1. Demographic profile of care provided at the IFOR Hospital between 2019 and 2020 (April to July).

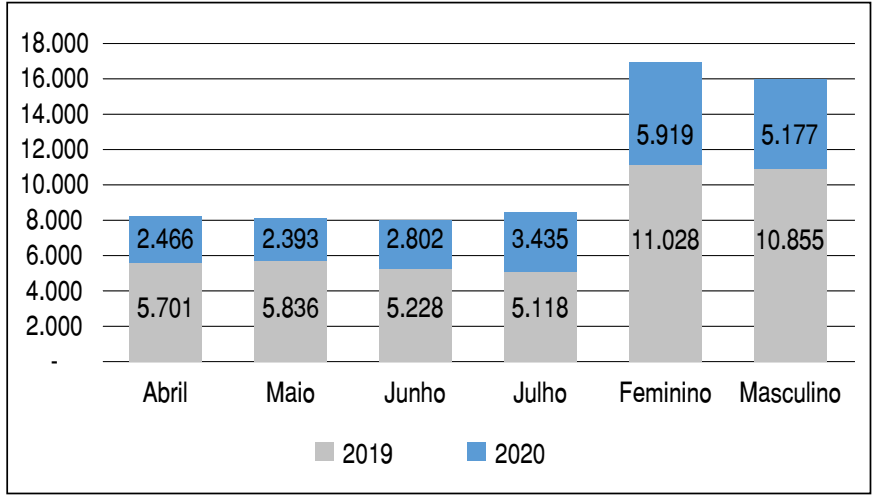

Results on the comparison of the total number of patients seen in 2019 and 2020 showed a difference of 10,787 (49.29\%).

The total number of patients operated for presenting injuries to the locomotor system resulting from orthopedic trauma in 2019 was 1,759. Of these, 934 (53.1\%) patients were male and 825 (46.9\%) were female. The average age was 44 years (minimum 6 years and maximum 98 years). The distribution of operated patients, according to the months of April, May, June and July was respectively 495 (28.14\%), 418 (23.77\%), 375 (21.31\%) and 471 (26.78\%). Information on the distribution of our material considering the control period is shown in Table 1.

Table 1. Demographic profile of surgeries performed in 2019

\begin{tabular}{|c|c|c|}
\hline MALE & 934 & $53.10 \%$ \\
\hline FEMALE & 825 & $46.90 \%$ \\
\hline \# Patients operated on & 1,759 & $100 \%$ \\
\hline \multicolumn{3}{|c|}{ Distribution of operated patients } \\
\hline APRIL & 495 & $28.14 \%$ \\
\hline MAY & 418 & $23.8 \%$ \\
\hline JUNE & 375 & $21.3 \%$ \\
\hline JULY & 471 & $26.8 \%$ \\
\hline \# Patients operated on & 1,759 & $100 \%$ \\
\hline \multicolumn{3}{|c|}{44 year old average } \\
\hline
\end{tabular}

The total number of patients operated in 2020 was 1,154. Of these, 563 (48.75\%) patients were male and 591 (51.25\%) female. The average age was 44 years (minimum 6 years and maximum 98 years). The distribution of operated patients, according to the months chosen for the study, was respectively 178 (15.42\%), 257 (22.27\%), 274 (23.74\%) and 445 (38.56\%). The information on the distribution of our sample, considering the period of the pandemic, is shown in Table 2. 
Table 2. Demographic profile of surgeries performed in 2020

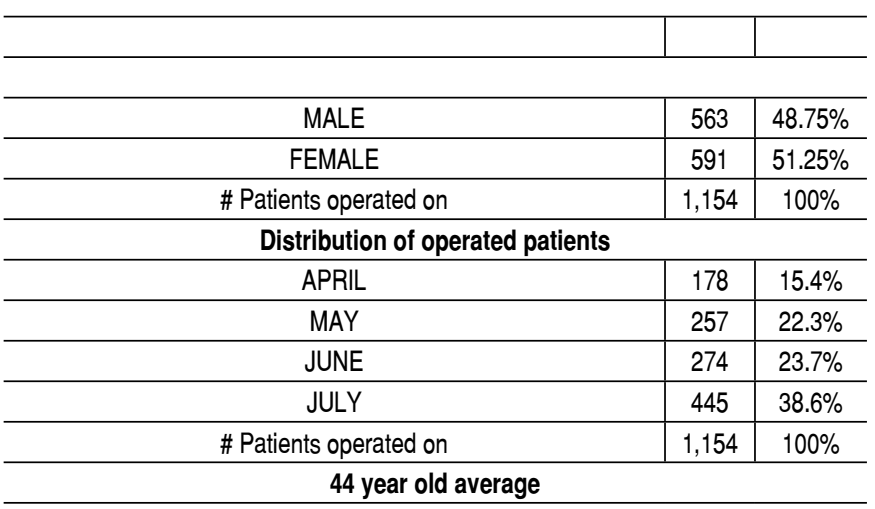

The overall reduction in the number of surgeries was 34.39\%.

The results obtained, comparing month by month, in the period determined by the researchers, showed a decrease for the variable surgery, respectively: April 317 (64.04\%), May 161 (38.51\%), June $101(26.93 \%)$ and July 26 (5.52\%).

In 2019 we observed the following diagnoses in descending order of frequency: lumbar spine pain with 3621 visits (16.55\%), joint pain with 3569 visits (16.54\%), neck pain with 1576 (7.2\%), sprain of ankle with 1304 (6\%) consultations, and limb pain with 863 (4\%) consultations. The information on the distribution of the material in this research, considering the control period, is shown in Table 3.

Table 3. Demographic profile of surgeries performed in 2019.

\begin{tabular}{|c|c|c|}
\hline Lumbar spine pain & 3,621 & $16.55 \%$ \\
\hline Arthralgia & 3,569 & $16.54 \%$ \\
\hline Neck pain & 1,576 & $7.20 \%$ \\
\hline Ankle sprain & 1,304 & $6.00 \%$ \\
\hline Limb Pain & 863 & $4.00 \%$ \\
\hline
\end{tabular}

Among patients treated in 2020, we observed the following diagnoses in descending order of frequency: lumbar spine pain with $2,082(18.76 \%)$ visits, joint pain with 1,645 (14.82\%), neck pain with 855 (7.7\%), ankle sprain with 467 (4.2\%) and limb pain with 393 (3.54\%). Information on the distribution of this sample is shown in Table 4.

Table 4. Demographic profile of surgeries performed in 2020.

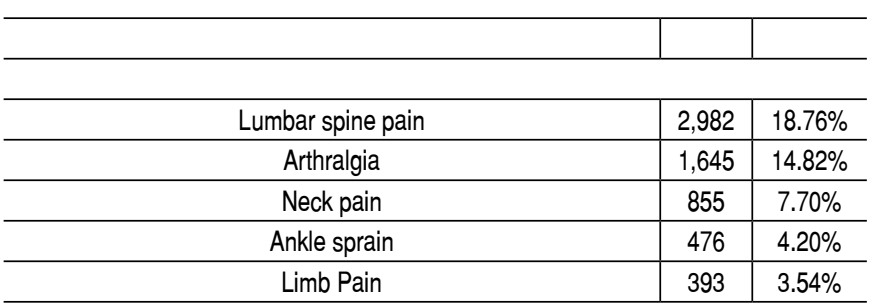

\section{DISCUSSION}

Researchers and health professionals face a constant and unprecedented challenge, caused by the lack of knowledge about
Covid-19. The high speed of dissemination and the considerable rate of lethality, especially in vulnerable populations ${ }^{8}$, generated uncertainties about what would be the best strategies to be used to face the consequences of its dissemination. 4,5,8,11,12

Emergency medical care must be prompt, safe and effective, and provide the easy access provided by an effective health care system. And the installation of the pandemic could provide a marked change in the routines and patterns of consultation in the search for emergency units. ${ }^{7}$

The data obtained by the TASY Phillips System, which is the electronic system used in our service, showed that the comparative analysis between the years 2019 and 2020 of the patients treated, in general, showed a significant decrease in care during the Covid-19 pandemic period. ${ }^{15,17,19}$

This result was influenced by a drastic change in the behavior of the population that remained away from parks, fields, sports arenas, gyms and other environments, resulting in a reduction in exposure to traumatic accidents.

During the study period, there was a drop of $49.3 \%$ in emergency room visits during the current period of the pandemic, which significantly disrupted the routine, corroborating the findings found in the literature. ${ }^{7}$ From the experience of previous pandemics, withdrawal behaviors included patients' reluctance to attend hospitals due to fear of contracting the disease. The hospital, object of study, has the characteristic of being essentially orthopedic, where consultations often result from complaints not related to trauma, where there was, notably, a drastic reduction, impacting this reduction in the total number of cases received.

Another aspect to consider is that there was also a reduction in visits for traumatic causes, although the decrease in frequency was less expressive (16\%) when compared to those represented by diagnoses of non-traumatic disorders. However, we noticed that there was a change in the pattern of fractures diagnosed based on information collected from the hospital's database when we compared the most prevalent ICD 10 in the 2020 period during the pandemic. We believe that social isolation, adopted in most parts of the country, has changed the routine of the Brazilian population. Such behavior culminated in a higher rate of domestic trauma and a lower rate of injuries caused by recreational and sports activities, determined by the progressive reduction in social isolation.

Considering the fractures of patients who were admitted to the emergency room, we observed an increase in the number of cases of fractures of the toes, accounting for 1\% of visits in 2019 and an increase to $3 \%$ in the same period in 2020 . There was an increase in these cases, as in 2019183 lesions were diagnosed and 371 in 2020. We noticed a decrease in the incidence of all other treated fractures. Domestic accidents, such as falling to the ground or direct trauma, became more prevalent in 2020.18,19

We observed that in a study carried out in Israel ${ }^{7}$ data on emergency calls by ambulances during the period of the pandemic were collected in order to assess the diagnosis for such contacts. The authors of this study noticed a significant increase in calls for clinical situations such as cough, hemoptysis, sore throat and fever, with a reduction in limb and head injuries, for example, showing a reduction in demands of traumatic origin. Such data reflect a change in the care profile, in general, in the emergency units, which is in part consistent with what was observed in the emergency care analyzed in this work. However, in the studied hospital, the decrease in attendances was global, since it is an emergency room dedicated exclusively to orthopedic assistance, therefore, not expecting an increase in the demand for this unit due to non-orthopedic complaints.

As the care profile of our hospital is essentially for Orthopedics and Traumatology, performing surgeries is an important gateway for patients. We also found that the performance of elective 
surgeries in general results in an increase in eventual visits to the emergency room.

Among the measures adopted by the federal and state government, it was determined that elective surgical interventions were systematically postponed or suspended ${ }^{1}$ that actually occurred during the study period, which indirectly influenced the change in the volume of emergency room visits. However, this variable was not studied by this work.

In our service, patients who arrived at the emergency room with respiratory complaints were treated in a separate and isolated place, determined exclusively for this type of care. On the other hand, patients who were going to undergo surgical procedures were tested through the qualitative detection of Coronavirus by the PCR method (PCR-COVID) and underwent a chest tomography exam. In urgent surgeries, the PCR-negative cases occurred without the need for isolation from the operating room and without the patient leaving the post-anesthetic recovery room. In PCR-positive cases or in cases where the test result was not yet available, the operating room was isolated, the number of participants reduced to the minimum possible, and all members were instructed to wear appropriate clothing and N95 masks. Anesthetic recovery was performed in the room where each procedure took place.

Therefore, there was an impactful change in the flow of the operating room, since contingency measures were adopted with the installation of specific institutional protocols. In addition to the patients, the medical teams and collaborators were systematically submitted to the PCR test for Covid-19. The isolation of the operating room and the patient's release flow received attention from the time he left the anesthetic recovery room until he was taken to his room. Thus, the operating room included in its daily planning: the determination of the estimated time for release from each room and for each type of patient; anticipate the need for isolation.
The main limitations found in this study are: the hospital mostly meets orthopedic demands, which makes it difficult to compare the results found in this study with those carried out in institutions with a different care profile; the profile of the service with the same period of the previous year was evaluated, which for the authors may represent a short period for fostering more definitive conclusions; The study was carried out with data from only one health institution, which prevented the authors from concluding whether the change in the profile of care in the emergency room during the study period was a global trend or exclusive to this institution. This is a retrospective study of data analysis from medical records that by itself determines the production of an article of lesser scientific relevance despite using an adequate methodology.

\section{CONCLUSIONS}

In this retrospective cross-sectional study, we noticed a drop of $49.3 \%$ in the number of visits over the months due to the influence of Covid-19. This resulted in a decrease in the number of consultations, especially in the first three months of the pandemic, considering the consultations in the emergency room resulting from orthopedic trauma

The reduction in the incidence of consultations was respectively in April 3,235 (56.8\%), May 3,443 (59\%), June 2,426 (46.4\%) and July $1,683(32.9 \%)$.

The overall reduction in the number of surgeries was $34.39 \%$.

Among the main diagnoses found during the pandemic period in descending order according to the ICD-10 were:

- Pain in the Lumbar Spine with 2,082 (18.76\%) visits;

- Joint Pain with 1645 (14.82\%) visits;

- Neck pain with 855 (7.7\%) visits;

- Ankle Sprain with 467 (4.2\%) visits;

- Pain in the limb with 393 (3.54\%) visits.

AUTHORS' CONTRIBUTION: Each author contributed individually and significantly to the development of this article. HVRQ: writing, data acquisition and analysis, data interpretation and project design; NENT: writing, data acquisition and analysis and project design; BGPO: writing, project design; MVFS: review of the article and intellectual concept of the article; ETD: review of the article, intellectual concept of the article and final approval of the version of the manuscript to be published.

\section{REFERENCES}

1. Flemming S, Hankir M, Ernestus RI, Seyfried F, Germer CT, Meybohm P, et al. Surgery in times of Covid-19 recommendations for hospital and patient management. Langenbecks Arch Surg. 2020;405(3):359-64.

2. Griffin KM, Karas MG, Ivascu NS, Lief L. Hospital preparedness for COVID-19: a practical guide from a critical care perspective. Am J Respir Crit Care Med. 2020;201(11):1337-44

3. Abd-Alrazaq A, Alhuwail D, Househ M, Hamdi M, Shah Z. Top concerns of tweeters during the Covid-19 pandemic: infoveillance study. J Med Internet Res. 2020;22(4):e19016.

4. Sun P, Lu X, Xu C, Sun W, Pan B. Understanding of Covid-19 based on current evidence. J Med Virol. 2020;92(6):548-51.

5. Cevik M, Bamford CGG, Ho A. Covid-19 pandemic-a focused review for clinicians. Clin Microbiol Infect. 2020;26(7):842-7.

6. Bulut C, Kato Y. Epidemiology of Covid-19. Turk J Med Sci. 2020;50(SI-1):563-70.

7. Jaffe E, Sonkin R, Strugo R, Zerath E. Evolution of emergency medical calls during a pandemic: an emergency medical service during the Covid-19 outbreak. Am J Emerg Med. 2021:43:206-6.

8. Li H, Liu SM, Yu XH, Tang SL, Tang CK. Coronavirus disease 2019 (Covid-19): current status and future perspectives. Int J Antimicrob Agents. 2020;55(5):105951.

9. Wang J, Pan L, Tang S, Ji JS, Shi X. Mask use during Covid-19: a risk adjusted strategy. Environ Pollut. 2020;266(Pt 1):115099.

10. Weston S, Frieman MB. Covid-19: knowns, unknowns, and questions. mSphere. 2020;5(2):e00203-20.

11. Tu H, Tu S, Gao S, Shao A, Sheng J. Current epidemiological and clinical features of Covid-19: a global perspective from China. J Infect. 2020;81(1):1-9. 12. Ludwig S, Zarbock A. Coronaviruses and SARS-CoV-2: a brief overview. Anesth Analg. 2020;131(1):93-6.

13. Kamel Boulos MN, Geraghty EM. Geographical tracking and mapping of coronavirus disease Covid-19/severe acute respiratory syndrome coronavirus 2 (SARS-CoV-2) epidemic and associated events around the world: how 21st century GIS technologies are supporting the global fight against outbreaks and epidemics. Int J Health Geogr. 2020;19(1):8.

14. Steffens I. A hundred days into the coronavirus disease (Covid-19) pandemic. Euro Surveill. 2020;25(14):2000550.

15. Wu D, Wu T, Liu Q, Yang Z. The SARS-CoV-2 outbreak: what we know. Int J Infect Dis. 2020;94:44-8.

16. Singhal T. A review of coronavirus disease-2019 (Covid-19). Indian J Pediatr. 2020;87(4):281-6.

17. Guo YR, Cao QD, Hong ZS, Tan YY, Chen SD, Jin HJ, et al. The origin, transmission and clinical therapies on coronavirus disease 2019 (Covid-19) outbreak: an update on the status. Mil Med Res. 2020;7(1):11.

18. Ahn DG, Shin HJ, Kim MH, Lee S, Kim HS, Myoung J, et al. Current status of epidemiology, diagnosis, therapeutics, and vaccines for novel coronavirus disease 2019 (Covid-19). J Microbiol Biotechnol. 2020;30(3):313-24.

19. Dubey S, Biswas P, Ghosh R, Chatterjee S, Dubey MJ, Chatterjee S, et al. Psychosocial impact of Covid-19. Diabetes Metab Syndr. 2020;14(5):779-88.

20. Milnik A, Lindholz M, Wenderoth H, Pietsch C. Covid-19 in der zentralen notaufnahme: übersicht über die klinische präsentation der ersten 35 patienten in der frühphase der pandemie [Covid-19 in the emergency room]. Notf Rett Med. 2020;22:1-4. 